\title{
Prevalence of Hepatitis B Virus Infection Among Patients with Chronic Kidney Disease in Jos University Teaching Hospital (JUTH) Jos, Nigeria
}

\author{
Jude Yunzoom Nkup ${ }^{1}$, Prisca Ofoeke ${ }^{1}$, Julius Ocheme Okojokwu ${ }^{1}$, Otobo Innocent Ujah ${ }^{3}$, \\ Emeka Ubah Ejeliogu ${ }^{2,4}$, Joseph Aje Anejo-Okopi ${ }^{1,2, *}$ \\ ${ }^{1}$ Department of Microbiology, Faculty of Natural Sciences, University of Jos, Jos, Nigeria \\ ${ }^{2}$ AIDS Prevention Initiative in Nigeria, Jos University Teaching Hospital, Jos, Nigeria \\ ${ }^{3}$ Department of Obstetrics and Gynecology, Jos University Teaching Hospital, Jos, Nigeria \\ ${ }^{4}$ Department of Pediatric, University of Jos, Jos, Nigeria
}

Email address:

josephokopi@yahoo.com (J. A. Anejo-Okopi)

${ }^{*}$ Corresponding author

\section{To cite this article:}

Jude Yunzoom Nkup, Prisca Ofoeke, Julius Ocheme Okojokwu, Otobo Innocent Ujah, Emeka Ubah Ejeliogu, Joseph Aje Anejo-Okopi. Prevalence of Hepatitis B Virus Infection Among Patients with Chronic Kidney Disease in Jos University Teaching Hospital (JUTH) Jos, Nigeria. American Journal of Laboratory Medicine. Vol. 3, No. 1, 2018, pp. 1-5. doi: 10.11648/j.ajlm.20180301.11

Received: September 23, 2017; Accepted: October 16, 2017; Published: December 5, 2017

\begin{abstract}
The frequency of hepatitis B virus in patients with CKD undergoing haemodialysis maintenance has a medical importance in the transmission of the infection and the cause of kidney disease. We aimed to determine sero-prevalence of HBV in patients with chronic kidney disease. A total of 110 blood samples were collected from nephrology Department of Jos University Teaching Hospital and screened for HBsAg marker. HBsAg was detected using rapid chromatographic immunoassays for qualitative detection of HBsAg and was performed using one-step test strips for detection of HBsAg in serum sample. Out of the 110 patients selected, 56 were males and 54 females with an overall $15.5 \% \mathrm{HBsAg}$ positivity. It was observed that HBsAg positive increases with prolonged duration of haemodialysis maintenance. The prevalence of $\mathrm{HBsAg}$ among Chronic Kidney Disease patients is high, however there was no significant association between HBV and chronic kidney disease in this cross-Sectional survey.
\end{abstract}

Keywords: HBV, Infection, Chronic Kidney Disease, JUTH

\section{Introduction}

Globally, it is estimated that more than 350 million people have chronic hepatitis $\mathrm{B}$ virus infection, with approximately 1 million dead each year due to liver disease and hepatocellular carcinoma [1]. Hepatitis B virus is an important cause of hepatitis in patients with chronic kidney disease (CKD) who are on regular hemodialysis as well as in renal transplant recipients [2].

Patients undergoing hemodialysis maintenance with end stage renal disease (ESRD) are at high risk of hepatitis $B$ infection [3]. Despite advances in controlling the transmission of HBV infection in dialysis units in the management of patients with end-stage renal disease [4],
HBV outbreaks continue to be reported, even in the developed world [5]. In developing countries like Nigeria, some explanations for such prevalence are obvious: a higher HBsAg prevalence in the general population; not very strict adherence to standard precautions and routine hemodialysis precautions; the absence of $\mathrm{HBV}$ vaccinations, and, of course, the lack of financial resources [6].

HBV infection is transmitted primarily through the parenteral route [7]. Other modes of transmission like sexual, vertical routes also have some role in transmission. The process of hemodialysis requires vascular access for prolonged period [8]. Furthermore, hemodialysis patients are immunosuppressed [9], that increases their susceptibility to infection requiring frequent hospitalization and surgery, 
which again increases their risk for exposure to nosocomial infection [8]. Although vaccination is routinely recommended in ESRD patients, antibody response to vaccination is suppressed and its level rapidly declines among patients on chronic dialysis due to the decreased immunological responses [10].

A study carried out in India on the prevalence of hepatitis $\mathrm{B}$ virus documented $8.8 \%$ and $14.2 \%$ in predialysis and hemodialysis group respectively [11]. Similarly, in Turkey, prevalence of $10.5 \%$ and $13.3 \%$ in predialysis and hemodialysis patients respectively [12] was reported. The prevalence of chronic hepatitis B virus (HBV) infection is high $(>8 \%)$ in sub-Saharan Africa. In Nigeria, there is paucity of data on the prevalence of Hepatitis B virus among patients with chronic kidney disease, hence, the need for this research.

\section{Materials and Methods}

\subsection{Study Population}

Jos University Teaching Hospital (JUTH) is located in Jos North Local Government Area (LGA) of Plateau State in Nigeria. It provides comprehensive health care services; also serves as a referral Centre for health facilities in other LGAs of the state and some neighboring states in the Country. A cross sectional study was carried out among consenting Chronic Kidney Disease (CKD) patients, infected patients on hemodialysis and those not on hemodialysis in the Department of Nephrology in JUTH. One hundred and ten (110) samples were collected for a period of three (3) months and stored at $-72^{\circ} \mathrm{C}$ before transporting to APIN Laboratories in Jos Plateau State, Nigeria.

\subsection{Ethical Consideration}

Approval of the study protocol was obtained from institutional 'Ethic Committee' at Jos University Teaching Hospital.

\subsection{Sample Collection and Processing}

$5 \mathrm{ml}$ of random whole blood sample was collected by venipuncture without venous stasis and dispensed into a plain separating bottle. The blood was allowed to clot and spun at $3000 \mathrm{rpm}$ for 5 minutes. Serum was separated into a sterile plain bottle and stored at $-20^{\circ} \mathrm{C}$ until analysis. One step HBsAg strip (Skytel Diagnostics, USA) a rapid chromatographic immunoassay for the quality detection of HBsAg serum/plasma was used to screen the participant's serum sample. The analysis was carried out following the manufacturer's instructions by applying few drops of the sample on the strip and monitored for ten (10) minutes. Positive HBsAg result is indicated by pink double bands on the strip; else, it is negative/invalid.

\subsection{Statistical Analysis}

Data were analyzed using statistical package for social sciences version 22 at $(\mathrm{P}<0.05)$ level of confidence and results tabulated.

\section{Results}

In this study, $110 \mathrm{CKD}$ patients were included. Among which 56 were males and 54 females with age range of 21-80 years. All patients were tested for HBsAg marker, of which seventeen, $17(15.5 \%)$ were positive and ninety three 93 (84.5\%) were negative. High HBsAg prevalence of $25.0 \%$ was recorded among age group of 71-80 years with male to female presenting with $12.5 \%$ and $18.5 \%$ prevalence (Table 1 ).

This study recorded a prevalence of $9.8 \%$ among those on haemodialysis. The seroprevalence of $\mathrm{HBsAg}$ in relation to the duration of haemodialysis was found to be $18.2 \%$ among those on haemodialysis for period of 6 months, $16.7 \%$ among those with duration of 1 year, and $12.5 \%$ among those with duration of above 2 years. The study also documented hypertension $6(16.2)$ as the most prevalent cause of CKD followed by Diabetis with $42(38.2 \%)$ of patients having history of blood transfusion (Table 2).

In table 3, the distribution of Hepatitis B Virus infection in relation to other risk factors such as piercing/tattooing of the skin, use of sharp objects, alcohol intake, invasive procedures, HIV and HCV status was presented. Though these risks factors were not significantly associated with HBV infection in this study, they have been reported to play important role in the course of the infection.

Table 1. Distribution of Hepatitis B Virus infection by age group among patients with Chronic Kidney Disease.

\begin{tabular}{llll}
\hline Age (years) & No. of sample & No. positive (\%) & No. negative (\%) \\
\hline $21-30$ & 16 & $1(6.3)$ & $15(93.8)$ \\
$31-40$ & 30 & $5(16.7)$ & $25(83.3)$ \\
$41-50$ & 26 & $6(23.1)$ & $20(76.9)$ \\
$51-60$ & 20 & $1(5.0)$ & $19(95.0)$ \\
$61-70$ & 14 & $3(21.4)$ & $11(78.6)$ \\
$71-80$ & 4 & $1(25.0)$ & $3(75.0)$ \\
Gender & & & 49.562 \\
Male & 56 & $7(12.5)$ & $49(87.5)$ \\
Female & 54 & $10(18.5)$ & $4.5)$ \\
Total & 110 & $17(15.5)$ & $93(84.5)$ \\
\hline
\end{tabular}


Table 2. Shows Distribution of HBV Infection in Relation to Risk Factors

\begin{tabular}{|c|c|c|c|c|c|}
\hline On Haemodialysis & No. of samples & No. positive (\%) & No. negative (\%) & $\chi^{2}$ & p-value \\
\hline Yes & 41 & $4(9.8)$ & $37(90.2)$ & 1.624 & 0.202 \\
\hline No & 69 & $13(18.8)$ & $56(81.2)$ & & \\
\hline Total & 110 & $17(15.5)$ & $93(84.5)$ & & \\
\hline \multicolumn{6}{|c|}{ Duration of Haemodialysis (months) } \\
\hline 3 & 12 & $0(0.00)$ & $12(100)$ & 3.011 & 0.556 \\
\hline 6 & 11 & $2(18.2)$ & $9(81.8)$ & & \\
\hline 12 & 6 & $1(16.7)$ & $5(83.3)$ & & \\
\hline$>24$ & 8 & $1(12.5)$ & $7(87.5)$ & & \\
\hline Total & 41 & $4(9.8)$ & $37(90.2)$ & & \\
\hline \multicolumn{6}{|l|}{ Cause of CKD } \\
\hline Hypertension & 37 & $6(16.2)$ & $31(83.3)$ & 4.928 & 0.177 \\
\hline Diabetes & 36 & $5(13.9)$ & $31(86.1)$ & & \\
\hline Unknown & 27 & $1(3.7)$ & $26(96.3)$ & & \\
\hline Others & 10 & $1(10.0)$ & $9(90.0)$ & & \\
\hline Yes & 42 & 5 (11.9) & $37(88.1)$ & 0.655 & 0.418 \\
\hline No & 68 & $12(17.6)$ & $56(82.4)$ & & \\
\hline Total & 110 & $17(15.5)$ & $93(84.5)$ & & \\
\hline
\end{tabular}

Table 3. Shows Distribution of Hepatitis B Virus Infection in Relation to other Risk Factors.

\begin{tabular}{|c|c|c|c|c|c|}
\hline Piercing/tattoo & No. of samples & No positive (\%) & No negative (\%) & $\chi^{2}$ & p-value \\
\hline Yes & 54 & $10(18.5)$ & $44(81.5)$ & 0.762 & 0.383 \\
\hline No & 56 & $7(12.5)$ & $49(87.5)$ & & \\
\hline Total & 110 & $17(15.5)$ & $93(84.5)$ & & \\
\hline \multicolumn{6}{|l|}{ Sharp objects } \\
\hline Yes & 60 & $11(18.3)$ & $49(81.7)$ & 0.837 & 0.360 \\
\hline No & 50 & $6(12.0)$ & $44(88.0)$ & & \\
\hline Total & 110 & $17(15.5)$ & $93(84.5)$ & & \\
\hline Yes & 22 & $4(18.2)$ & $18(81.8)$ & 0.157 & 0.692 \\
\hline No & 88 & $13(14.8)$ & $75(85.2)$ & & \\
\hline Total & 110 & $17(15.5)$ & $93(84.5)$ & & \\
\hline \multicolumn{6}{|l|}{ Invasive } \\
\hline Yes & 42 & $4(9.5)$ & $38(90.5)$ & 1.829 & 0.176 \\
\hline No & 68 & $13(19.1)$ & $55(80.9)$ & & \\
\hline Total & 110 & $17(15.5)$ & $93(84.5)$ & & \\
\hline Negative & 52 & $9(17.3)$ & $43(82.7)$ & & \\
\hline Total & 58 & $10(17.2)$ & $48(82.8)$ & & \\
\hline \multicolumn{6}{|l|}{$\mathrm{HCV}$} \\
\hline Positive & 5 & $0(0.0)$ & $5(100.0)$ & 1.446 & 0.229 \\
\hline Negative & 48 & $11(22.9)$ & $37(77.1)$ & & \\
\hline Total & 53 & $11(20.8)$ & $42(79.2)$ & & \\
\hline
\end{tabular}

\section{Discussion}

Patients suffering from chronic kidney disease, acute renal failure, chronic renal failure and other end stage renal diseases are those who have complete or insufficient kidney functions to remove waste products from blood. Therefore they need a continuous artificial mechanism to clean their blood and remove harmful nitrogenous wastes that can damage body in different ways. Patients with renal diseases undergo dialysis. Frequency of dialysis depends on patient's requirement. Due to multiple practices of dialysis, these patients are more prone to $\mathrm{HBsAg}$ infection [13].

This study revealed a prevalence of $17(15.5 \%) \mathrm{HBsAg}$ among CKD patients. Although, this is not surprising, because the endemicity of HBV infection in the general population. High prevalence prior to dialysis has been reported as a major risk factor for the transmission of infection in dialysis procedures [14]. It is therefore strongly recommended that CKD patients who are HBV negative be immunized routinely especially prior to dialysis.

The findings of $9.8 \% \mathrm{HBsAg}$ prevalence associated with CKD patients in this study is similar with the observation of by Amira and Lesi in Lagos, Southern part of Nigeria, who reported that $35(9.5 \%)$ of the patients with CKD were HBsAg positive and were 2 times more likely to have HBV infection. Another study from South Africa found that 24\% of black children with nephrotic syndrome were HBsAg positive and they all had membranous Glomerular Nephritis (GN) [15]. Moreover, in another study conducted by [16], 
$33 \%$ of the patients with GN were HBsAg positive compared with $6 \%$ in controls

HBsAg was observed to be significantly associated with increasing age. In this study, HBsAg was documented to be most prevalent between age group in the $4^{\text {th }}$ and $7^{\text {th }}$ decades. This is similar to the reports of [17] in Maiduguri, North Eastern Nigeria. This observation follows the assertion that vertical transmission may not play a major role in the spread of HBV infection in Nigeria [18]. Almost an equal proportion of male to female was represented in this study with the female having a higher prevalence 10 (18.5) of infection due to the ease of transmission during sexual intercourse compare with 10 (12.5) in males. This finding however did not agree with the reports of [19], who reported a higher prevalence in males. The variation could arise as a result of differences in the ratio of male to female use for the individual researches.

Data also shows higher preponderance of positive HBsAg among patients with prolonged duration of haemodialysis maintenance thereby increasing the risk of acquiring the infection. More so, delay in the appearance of serological markers for HBV by as long as $6-12$ months may as well be attributed. Patients with hypertension were more likely to be HBsAg positive $6(16.2 \%)$ compared to those with Diabetis 5 (13.9\%) or other causes of chronic Kidney Disease. The high prevalence of $15.5 \%$ presented in this study could be associated with some other risk factors such as unprotected sexual behavior, tattooing/ piercings, use of sharp objects, invasives.

High prevalence of HBsAg among the study group was observed with an increase risk of acquiring the disease due to prolonged duration of haemodialysis maintenance. However, there is no significant association between HBV and chronic kidney disease in this crossectional survey. The study was performed using immunochromatography strips for detection of HBsAg which gives qualitative result for the presence or absence of HBV infection. Advanced techniques could be employ which are more accurate and give quantitative results, however they were a constraint for this research.

\section{Conflict of Interest}

Authors declare that there is no conflict of interest.

\section{Acknowledgements}

The authors wish to express their gratitude to the patients for participating in this research. We are indebted to the staff and management Nephrology unit, Jos University Teaching Hospital and staff of the hepatitis serology unit of the AIDS Prevention Initiative Nigeria (APIN) laboratory for their technical assistance.

\section{References}

[1] M. J. Alter, and E. E. Mast. The epidemiology of viral hepatitis in the United States. Gastroenterol Clin North Am; (23): 437-455, 1994.
[2] U. Petr. Viral Hepatitis Infections in Chronic Kidney Disease Patients and Renal Transplant Recipients. Kidney Blood Press Research; (35): 454-467, 2012.

[3] A. E. Otedo, S. O. MC Ligeyo, F. A. Okoth, and J. K. Kayima. Seroprevalence of hepatitis B and hepatitis C in maintenance dialysis in a public hospital in a developing country. South African Medical Journal; 93: 380-4, 2003.

[4] L. Finelli, J. T. Miller, J. I. Tokars, M. J. Alter, and M. J. Arduino. National surveillance of dialysis associated diseases in the United States. Semin Dial; (18): 52-61, 2005.

[5] L. A. Kondili, D. Genovese, C. Argentini, P. Chionne, P. Toscani, R. Fabro, R. Cocconi, and M. Rapicetta. Nosocomial transmission in simultaneous outbreaks of hepatitis C and B virus infections in a haemodialysis center. European Journal of Clinical Microbiology and Infectious Diseases; (25): 527$531,2006$.

[6] Center for Disease Prevention and Control (CDC). Recommendations for preventing transmission of infections among chronic hemodialysis patients. MMWR Recomm Rep; 50 (RR-5): 1-43, 2001.

[7] S. A. Teles, R. M. B. Martins, C. L. R. Lopes, M. A. Carneiro, K. P. Souza, and C. F. T. Yoshida. Immunogenicity of a recombinant hepatitis B vaccine (Euvax-B) in a hemodialysis patients and staff. Europian Journal of Epidemiology; (17): 145-49, 2001.

[8] S. U. Busek, E. H. Baba, E. Tavares, H. A. Filho, L. Pimenta, A. Salomao, R. Correa Oliveira, and G. C. Oliveira. Hepatitis $\mathrm{C}$ and hepatitis $\mathrm{B}$ virus infection in different hemodialysis units in Belo Horizonte, Minas Gerais, Brazil. Mem Inst Oswaldo Cruz; (97): 775-778, 2002.

[9] M. Devesa, Y. E. Khudyakov, F. Capriles, L. Blitz, H. A. Fields, F. Liprandi, and F. H. Pujol. Reduced Antibody Reactivity to Hepatitis C Virus Antigens Hemodialysis Patients Coinfected with Hepatitis B Virus. Clinical and Diagnostic Laboratory Immunology; (4): 639-642, 1997.

[10] N. K. C. Tong, J. Beran, S. A. Kee, J. L. Miguel, C. Sanchez, J. M. Bayas, A. Vilella, J. R. De Juanes, P. Arrazola, F. C. Torrecillas, E. L. De Novales, V. Hamtiaux, M. Lievens, and M. Stoffel. Immunogenicity and safety of an adjuvanted hepatitis B vaccine in pre-dialysis and hemodialysis patients. Kidney Int; (68): 2298-2303, 2005.

[11] S. Chattopadhyay, S. Rao, B. C. Das, N. P. Singh, and P. Kar. Prevalence of transmitted virus infection in patients on maintenance hemodialysis from New Delhi, India. Hemodial Int; (9): 362-6, 2005.

[12] D. Sit, A. K. Kadiroglu, H. Kayabasi, M. E. Yilmaz, and V. Goral. Seroprevalence of hepatitis B and C viruses in patients with chronic kidney disease in the predialysis stage at a university hospital in Turkey; (50): 133-7, 2007.

[13] W. A. Alashek, C. W. Meintyre, and M. W. Taal. Hepatitis B and $\mathrm{C}$ infection in hemodialysis patients in Libya: prevalence incidence and risk factors. BMC Infect Dis 12: 265, 2012.

[14] J. K. Unger, and H. Peters. Hepatitis B in chronic kidney disease: Moving toward effective prevention. Kidney Int; (73): 799-801, 2008.

[15] R. Bhimma, H. M. Coovadia, and M. Adhilari. Hepatitis B virus -associated nephropathy membranous nephropathy in black South African children. Pediatr Nephrol; (11): 429-34, 1998. 
[16] A. Akinsola, O. Olusanya, A. O. Iyun, and, C. O. Mbanefo. Role of hepatitis Bs antigen in chronic glomerulonephritides in Nigerians. Afr J Med Med Sci; 13: 33-9, 1984.

[17] D. N. Bukbuka, A, P. Barsi, and Z. M. Mungoro. Seroprevalence of hepatitis B surface antigen among primary school pupils in rural Hawal Valley, Borno State, Nigeria. Nigeria. Journal of Community Medicine and Primary Health Care; 17 (1): 20-23, 2005.
[18] E. Marirnier, V. Barrois, B. Larouze, W. T. London, A. Cofer, L. Diakhate, and B. S. Blumberg. Lack of perinatal transmission of hepatitis B virus infection in Senegal, West Africa. Journal of Paediatrics; 106 (5): 843-849, 1985.

[19] K. Anwar, M. Imran, F. Shahzad, M. Noreen, M. Atif. Prevalence of Hepatitis B and Hepatitis C Infection among Patients Undergoing Dialysis. Journal of Human Virology and Retrovirology; 3 (3). 